\title{
PELATIHAN DESAIN SAMPUL DENGAN MS.WORD : MEMBUAT TUGAS SEKOLAH SISWA YATIM MARGA MULYA BEKASI LEBIH MENARIK DI PANDEMI COVID-19
}

\section{COVER DESIGN TRAINING WITH MS.WORD : MAKE SCHOOL ASSIGNMENTS ORPHAN STUDENTS MARGA MULYA BEKASI IS MORE INTERESTING ON THE COVID-19 PANDEMIC}

\author{
Budi Indrawati*, Elia Rossa, Tyna Yunita, Tutiek Yoganingsih \\ Fakultas Ekonomi dan Bisnis Universitas Bhayangkara Jakarta Raya, \\ Jalan Perjuangan Raya Bekasi \\ *Email: indrawati.budi5@gmail.com \\ (Diterima 02-09-2021; Disetujui 24-09-2021)
}

\begin{abstract}
ABSTRAK
Pada masa pandemi, kegiatan belajar mengajar otomatis menggunakan pembelajaran jarak jauh online, sehingga latihan dan tugas-tugas siswa semua melalui cara online, dan sebagian guru memberi tugas sekolah. Agar tetap memberikan semangat belajar pada masa pandemi covid-19 dan menambah nilai yang lebih baik pada tugas-tugas sekolah, maka pada cover tugas sekolah diberikan desain yang menarik. Kegiatan pengabdian kepada masyarakat ini diperuntukan bagi siswa Sahabat Yatim Marga Mulya Bekasi Utara. Tujuan kegiatan ini adalah memberikan pengetahuan dan ketrampilan pada masa pandemi covid-19, yaitu mendesain cover makalah, atau klipping menggunakan Microsoft Word, menambah wawasan di bidang teknologi informatika bahwa dengan Word dapat mendesain cover makalah, buku dan lainnya, dapat dijadikan hobby yang positif, memberikan ketrampilan yang bermanfaat untuk bekal dalam lapangan kerja nantinya, dapat pula dikembangkan menjadi suatu kegiatan usaha pada bidang percetakan, fotocopy, rental komputer dan sebagainya. Bahan peralatan yang digunakan laptop, infokus, modul, note book, bolpen. Metode yang digunakan adalah metode praktek langsung oleh siswa. Hasil dari kegiatan ini adalah peserta dapat menggunakan Word untuk membuat desain cover makalah, buku dan tugas sekolah dengan baik. Hasil penilaian peserta terhadap materi, instruktur, penyelenggaraan dan fasilitas pendukung, diperoleh nilai bobot semua di atas $81 \%$. Artinya berada pada interpretasi bahwa peserta menunjukkan reaksi positif yang tinggi. Kesimpulan bahwa peserta puas terhadap pelatihan menggunakan Word untuk desain cover. Saran perlu pelatihan komputer excel dan kerajinan tangan lainnya.
\end{abstract}

Kata Kunci : Desain Cover, Microsoft Word, Pelatihan

\begin{abstract}
During the pandemic, teaching and learning activities are automated using online distance learning, so that students' exercises and assignments are all online, and some teachers give school assignments. In order to keep the spirit of learning during the covid-19 pandemic and add better grades to school assignments, the cover of school assignments is given an attractive design. This community service activity is intended for students of Friends of Orphans Marga Mulya, North Bekasi. The purpose of this activity is to provide knowledge and skills during the covid-19 pandemic, namely designing paper covers, or clippings using Microsoft Word, adding insight in the field of information technology that with Word you can design paper covers, books and others, can be used as a positive hobby, provide useful skills for future employment, can also be developed into a business activity in the field of printing, photocopying, computer rental and so on. Equipment materials used are laptops, infocus, modules, note books, pens. The method used is a direct practice method by students. The result of this activity is that participants can use Word to make good cover designs for papers, books and school assignments. The results of the participants' assessment of the materials, instructors, implementation and supporting facilities, obtained a weight value of all above $81 \%$. This means that it is in the interpretation that participants show a high positive reaction. The conclusion that the participants were satisfied with the training using Word for cover design. Suggestions need excel computer training and other crafts.
\end{abstract}

Keywords : Cover Design, Microsoft Word, Training 
Pelatihan Desain Sampul Dengan MS.Word : Membuat Tugas Sekolah Siswa Yatim Marga Mulya Bekasi Lebih Menarik

\section{PENDAHULUAN}

Pandemi Covid-19 telah merubah metode pembelajaran yang diselenggarakan oleh sekolah. Dalam waktu cepat, kampus dan sekolah dipaksa untuk melaksanakan pembelajaran daring. Ada sekitar $97 \%$ perguruan tinggi telah mengadopsi pembelajaran daring (Nizam, 2020).

Konsep merdeka belajar adalah kemerdekaan unit pendidikan untuk melakukan inovasi. Oleh karena itu, pengajar bersama siswa dapat melakukan bersama dan membuat suatu inovasi dalam belajar, yang tentunya disesuaikan dengan budaya, agama, sosio ekonomi dan kearifan lokal.

Dalam masa pandemi, kegiatan belajar mengajar otomatis menggunakan pembelajaran jarak jauh online, jika jenuh dengan kegiatan tanpa tatap muka langsung ini, dapat melakukan tatap muka dengan zoom atau google meet atau aplikasi lainnya, serta bentuk variasi dalam pemberian soal dan pertanyaan, dan dengan lebih banyak memberikan contoh-contoh dan latihan, terutama contoh sederhana. Dalam masa pandemi, kegiatan inovasi belajar memang sangat tergantung kepada teknologi, oleh karenanya pengajar maupun siswa harus update dalam teknologi.

Semua kegiatan sekolah telah dilakukan dengan cara online, sehingga latihan dan tugas-tugas siswa semua melalui cara online dikirim dalam bentuk file ke guru-guru, dan hampir semua guru memberi tugas sekolah.

Jika pembelajaran jarak jauh (PJJ) berlangsung dalam waktu yang lama dan terusmenerus, serta tidak dapat dipastikan kapan akan berakhir, maka akan muncul kejenuhan dalam belajar online. Jika kejenuhan tersebut tidak segera diatasi, maka akan menyebabkan tidak optimalnya proses belajar-mengajar yang berujung pada hasil pembelajaran yang tidak memuaskan. Belajar daring online memang tidak sesempurna belajar di kelas secara tatap muka langsung. Untuk itulah kami Tim Pengabdian Kepada Masyarakat membantu memberikan pengetahuan dan wawasan kepada siswa remaja sekolah dalam mengatasi salah satu problem yang muncul dari belajar daring yang berlangsung secara terus menerus. Yaitu melalui kegiatan pelatihan desain cover makalah atau cover klipping dan tugas sekolah lainnya. sehingga warna-warni desain cover tersebut menjadi daya tarik dalam belajar dan bekerja. Sekaligus menambah nilai bagi makalah atau tugas-tugas sekolah yang diberi desain cover tersebut.sekaligus dapat menjadi suatu hobby dalam bidang desain grafis yang dimulai dari tingkat menengah (SMP) maupun atas (SMA). 
Urgensi dari kegiatan pengabdian kepada masyarakat ini adalah melalui pelatihan desain cover ini diharapkan dapat menghilangkan kejenuhan bagi siswa remaja sekolah dalam belajar online, karena melalui desain cover ada hal yang baru dan menarik dalam pembuatan tugas-tugas sekolah melalui Microsoft Word, dimana mereka dapat berkreasi melalui gambar dan desain serta warna.

Pengguna Microsoft Word mungkin banyak yang tidak mengetahui tentang Microsoft Word for design. Umumnya perangkat lunak ini memang ditujukan untuk mengolah kata dan data. Kemampuannya sebagai word processor memang tidak diragukan, tetapi untuk desain, banyak yang masih tidak mengetahui, bahkan hampir semua penggunanya tidak mengetahui sama sekali tentang hal ini.

Dengan fasilitas yang disediakan perangkat lunak ini, dapat membuat desain-desain indah dan menawan dengan hasil yang berkualitas tinggi, dan jika di print, ketajaman gambarnya cukup baik berkualitas. Desain-desain yang cantik dan menarik tidak kalah dengan desain yang dihasilkan dari menggunakan perangkat lunak desain sebenarnya (Larenta Apriyanti, 2020).

Dari pengabdian kepada masyarakat terdahulu mengungkapkan bahwa pengetahuan tentang pemanfaatan komputer di lingkungan siswa remaja masih minim, sehingga peningkatan kompetensi yang mereka miliki kurang optimal. Hal ini mengakibatkan kreatifitas menjadi terhambat. Dengan memanfaatkan komputer serta aplikasinya, diharapkan siswa remaja mampu untuk bersaing dan meningkatkan kreatifitas yang akan menjadi kompetensi mereka. Potensi yang dimiliki oleh mitra siswa diantaranya adalah kreatifitas dari para remaja (Raafi'udin, 2020).

Sahabat Yatim Indonesia (SAYATI) merupakan sebuah lembaga sosial yang bergerak dalam bidang pengasuhan dan pemberdayaan anak-anak yatim dan dhuafa. Berdiri sejak September 2009, Sahabat Yatim Indonesia mengawal mereka menuju masa depan yang lebih gemilang di tengah kesulitan dan ketidakberdayaan karena kehilangan orang tua dan himpitan kemiskinan (sahabatyatim.com, 2021). Untuk itu, melalui kegiatan pengabdian kepada masyarakat dalam bentuk pelatihan desain cover ini, diharapkan dapat memberikan ketrampilan bagi anak-anak yatim dan dhuafa, jika mereka bekerja nantinya, bahkan dapat menjadi suatu kegiatan wirausaha.

Di sekolah, siswa sahabat yatim dan dhuafa telah belajar menggunakan komputer, Microsoft Word, sehingga diharapkan tidak terlalu sulit dalam menggunakan Word untuk desain cover. Dengan pelatihan Word untuk desain cover, berarti telah mengenalkan perkembangan teknologi informatika. 
Pelatihan Desain Sampul Dengan MS.Word : Membuat Tugas Sekolah Siswa Yatim Marga Mulya Bekasi Lebih Menarik

Melalui Microsoft Word dapat membuat desain-desain yang menarik dan tidak kalah menarik dengan aplikasi desain grafis yang sebenarnya, sehingga melalui kegiatan pelatihan ini diharapkan dapat menimbulkan kreatifitas siswa remaja, mulai dari hobby hingga dapat menjadi pendapatan tersendiri nantinya seperti melalui kegiatan rental komputer dan percetakan. Tujuan dari kegiatan pengabdian kepada masyarakat ini: 1) Diharapkan dapat menimbulkan semangat baru bagi siswa remaja sekolah pada masa pandemi covid-19. 2) Diharapkan peserta dapat menggunakan Microsoft Word untuk membuat desain cover makalah klipping tugas sekolah. 3) Diharapkan menambah wawasan di bidang teknologi informatika. 4) Diharapkan dapat menjadi tempat timbulnya kreativitas siswa remaja dan hobby yang positif. 5) Diharapkan memberikan pengetahuan dan keterampilan penggunaan komputer Microsoft Word yang bermanfaat sebagai bekal dalam lapangan kerja nantinya.

\section{BAHAN DAN METODE}

Kegiatan pengabdian kepada masyarakat ini berbentuk pelatihan membuat desain cover makalah tugas-tugas sekolah dengan menggunakan Microsoft Word sehingga menjadi lebih indah dan menarik pada masa pandemi covid-19 ini.

Lokasi kegiatan pengabdian kepada masyarakat dilaksanakan di Asrama Sahabat Yatim Indonesia Jalan Raya Perjuangan Marga Mulya Bekasi Utara. Waktu pelaksanaan kegiatan pengabdian kepada masyarakat dilaksanakan pada hari Rabu, tanggal 25 Agustus 2021.

Kelompok sasaran kegiatan pengabdian kepada masyarakat ini adalah siswa sekolah menengah dan atas yang ada di bawah binaan asrama Sahabat Yatim Indonesia Kelurahan Marga Mulya Bekasi Utara.

Untuk kegiatan pengabdian kepada masyarakat ini, Tim PKM mempersiapkan segala sesuatu yang menyangkut teknis pelaksanaan sebagai berikut: 1) Perizinan ke Yayasan Rumah Sahabat Yatim Indonesia. 2) Pendataan siswa tingkat SMP atau SMA sebagai peserta. 3) Menyiapkan bahan materi pelatihan. 4) Menyiapkan peralatan untuk pelatihan: laptop dan infokus. 5) Mempersiapkan kuesioner untuk evaluasi pelatihan.

Metode pelatihan desain cover diawali dengan presentasi Word, kemudian instruktur mempraktekkan cara menggunakan Word untuk desain cover dan peserta mengikuti dengan seksama serta mempraktekkannya, tahapan pelaksanaan pelatihan desain cover makalah: 1)Persiapan awal. 2) Pengenalan secara umum penggunaan Word. 3) Praktek membuat desain cover makalah. 4) Evaluasi pelatihan. 


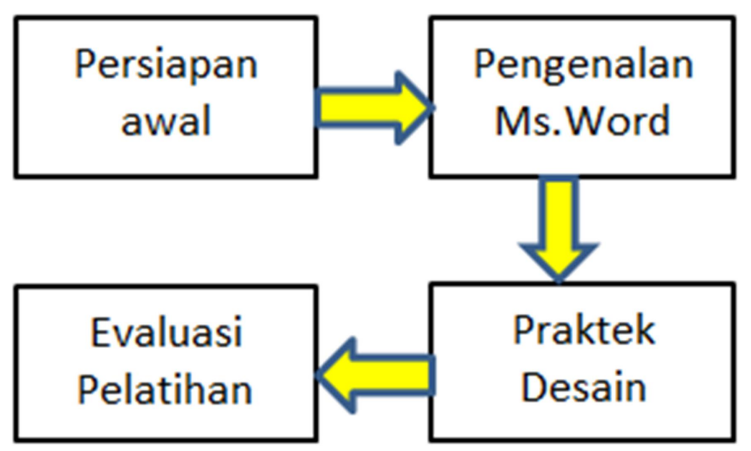

Gambar 1. Metode Pelaksanaan Pelatihan

Pada tahap persiapan awal, persiapan melakukan pertemuan dengan pimpinan asrama Sahabat Yatim Indonesia Marga Mulya Bekasi Utara, membicarakan rencana pelaksanaan kegiatan, memutuskan bentuk kegiatan, tempat kegiatan, perlengkapan kegiatan dan sarana, serta hari dan tanggal kegiatan.

Pada tahap pengenalan Word, tahap ini memperkenalkan secara umum penggunaan program Microsoft Word untuk pengolah kata sekaligus untuk desain cover.

Pada tahap praktek, dilakukan praktek cara pembuatan desain cover makalah atau buku dengan menggunakan Word dibantu dengan handout atau modul yang dibagikan kepada setiap peserta, agar peserta mudah untuk memahami dan mempraktekkan di sekolah nantinya setelah selesai pelatihan. Beberapa bagian dari handout sebagai berikut (Contohposter.com, 2020):

Langkah-langkah sebagai berikut:

1. Buka Ms.Word: Hidupkan Komputer / Laptop dan buka New Document

2. Atur Layout, Pilih Menu Page Layout, Klik Size, Klik A4

3. Pilih Menu Margin, Klik Custom Margins

4. Akan tampil kotak dialog sebagai berikut, isikan untuk Top...Left...Buttom...Right....dengan angka nol, dan klik ok,

5. Akan tampil kotak dialog di bawah ini, klik Fix.

6. Pertama membuat gambar Segitiga Siku-Siku : Pilih Menu Insert, Klik Shapes, Klik Segitiga Siku-Siku

7. Letakan Segitiga Siku-Siku pada lembar kertas kerja.

8. Atur ukuran / size segitiga dengan menggunakan menu Pilih Format, lihat di kanan atas, Ukuran tinggi segitiga dibuat kira-kira $9 \mathrm{~cm}(1 \mathrm{~cm}=0,394$ inch), berarti $9 \mathrm{~cm}=$ 3,5 inch jika laptopnya menggunakan ukuran inch), sedangkan lebar segitiga, mengikuti lebar kertas. Lihat menu size di kanan atas layar monitor. 
Pelatihan Desain Sampul Dengan MS.Word : Membuat Tugas Sekolah Siswa Yatim Marga Mulya Bekasi Lebih Menarik di Pandemi Covid-19

Budi Indrawati, Elia Rossa, Tyna Yunita, Tutiek Yoganingsih

9. Kemudian Segitiga Siku-Siku dibalik : Pilih Menu Format, Klik Rotate, Klik Flip Vertikal. Seperti Gambar 2.

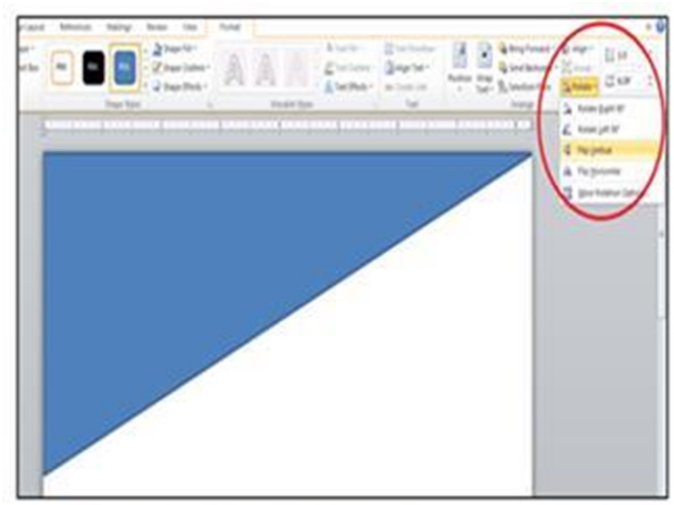

Gambar 2. Diawali membuat segitiga siku

10. Setelah segitiga dibalik, hilangkan garis pinggir segitiga : Klik segitiga dan Pilih Menu Format, Klik Shape Outline dan Klik No Outline.

11. Perbesar tampilan Word agar lebih mudah untuk mengedit gambar.

12. Geser segitiga ke bawah sedikit, agar mudah untuk merubah bentuk menjadi melengkung atau oval.

13. Rubah garis diagonal segitiga menjadi melengkung/oval : Cara Pilih Menu Format, Klik Edit Shape dan Klik Edit Point, sehingga pada segitiga muncul titik hitam di setiap sudut segitiga serta garis merah di pinggir segitiga, tandanya segitiga siap untuk di edit.

14. Edit gambar dimulai dengan klik titik hitam bagian sudut kiri bawah segitiga, dan muncul titik putih di bagian garis diagonal. Klik titik putih tersebut sambil ditarik ke bawah sesuai dengan bentuk lengkung yang diinginkan (Gambar 3 kiri).

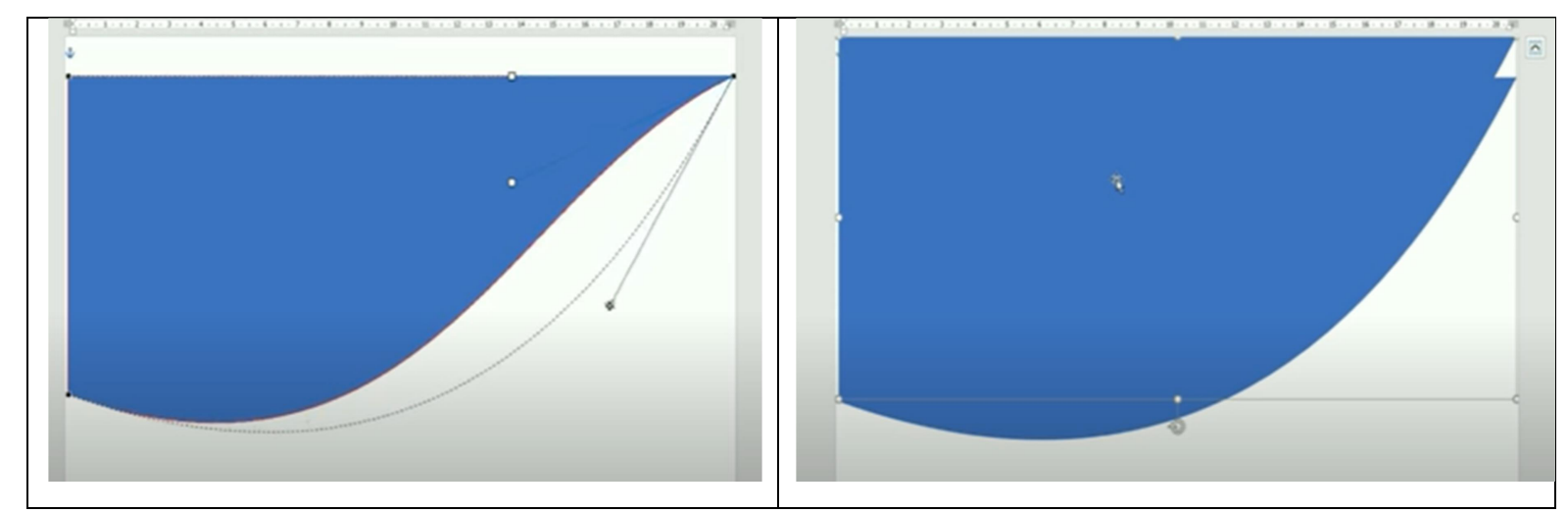

Gambar 3. Segitiga dirubah melengkung dan dicopy paste

15. Demikian pula dengan Klik titik hitam di sudut kanan atas segitiga, akan muncul titik putih ditengah garis diagonalnya, dan klik titik putih tersebut serta tarik ke bawah sesuai ukuran lengkung yang diinginkan. 
16. Setelah bentuk lengkung selesai, kemudian copy segitiga tersebut dengan cara : Klik segitiga dan tekan tombol Ctrl pada keyboard dan tarik/ drag ke atas sehingga ada dua gambar segitiga menumpuk (Gambar 3 kanan).

17. Untuk memudahkan pengaturan gambar segitiga, maka segitiga bagian atas warnanya dibedakan dengan merubah warnanya dengan warna abu-abu, dengan cara klik segitiga warna abu-abu, Pilih Menu Format, klik Shape Fill, Pilih warna abu-abu, berikutnya atur posisinya (selebar kertas) (Gambar 4 kiri).

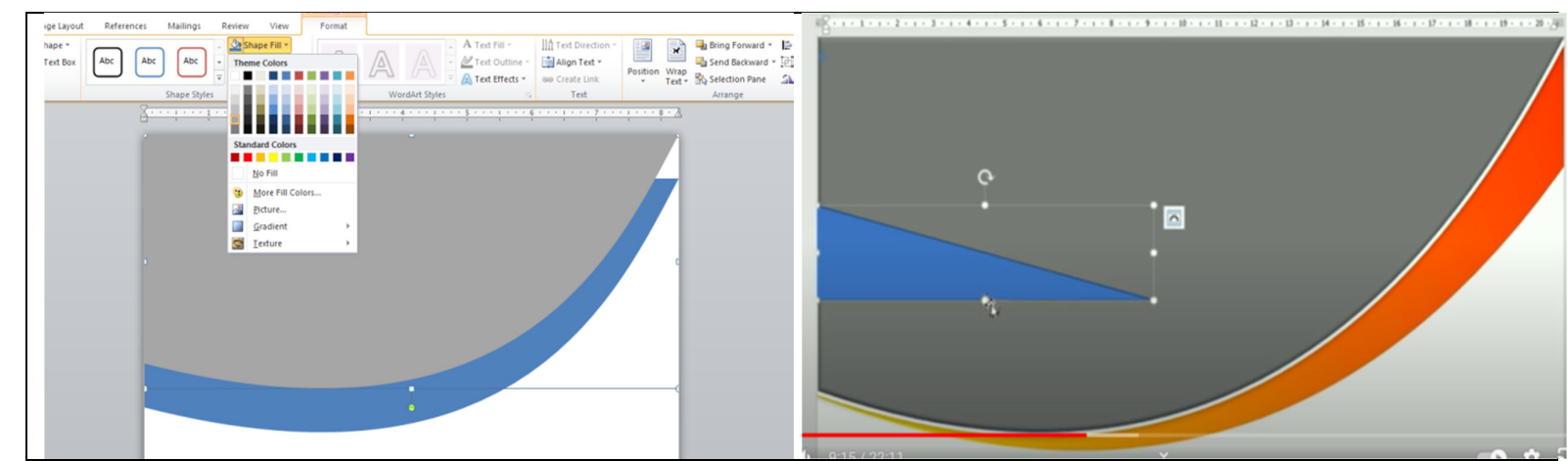

Gambar 4. Segitiga lengkung atas diberi warna abu-abu dan bawah merah

18. Kemudian segitiga warna biru diperbesar ukuran gambarnya dengan cara ditarik salah satu sudut, tarik dari sudut kiri dan kemudian dorong gambar segitiga abu-abu ke atas. Jika sebelah kanan kurang besar, dapat ditarik dari sudut kanan ke arah kanan

19. Kemudian segitiga berwarna biru di dorong ke atas kanan, di bawah segitiga abu-abu.

20. Setelah posisi segitiga biru sudah tepat, ganti warna biru dengan warna orange dan kuning, gunakan warna gradiasi. Caranya klik segitiga biru (objek yang akan diganti warnanya), dan klik mouse kanan sehingga muncul jendela menu, pilih Menu Format Shape (Gambar 4 kanan).

21. Tampil jendela Menu Format Shape, Klik Fill, Klik Gradien Fill, dan Pada bagian Type Pilih Linear, pada Bagian Angle pilih 20"

22. Pada bagian Gradien Stops pilih warna-warna yg diinginkan, dalam hal ini digunakan hanya 3 warna saja, jika stops yang tampil lebih dari tiga, maka stops lainnya dibuang/dikurangi, sehingga tersisa tiga.

Cara menghapus stops, klik Kotak yg akan dihilangkan pada Gradient Stops dan Klik Tombol Remove (sebelah kanan tanda silang merah). Sehingga tersisa tiga dan atur posisinya (jaraknya) dengan cara ditarik. Stops paling kanan ganti warna merah (dengan cara Klik Stop yang akan diganti warnanya, dan klik warna merah). Begitu pula selanjutnya Stops tengah beri warna orange, dan stops kiri warna kuning. Hasilnya segitiga warna biru berubah menjadi merah, orange dan kuning (Gambar 5). 
Pelatihan Desain Sampul Dengan MS.Word : Membuat Tugas Sekolah Siswa Yatim Marga Mulya Bekasi Lebih Menarik

23. Untuk segitiga warna abu-abu diberi effek dengan klik segitiga warna abu-abu. Pilih Menu Shape Effects, Pilih Presets dan Pilih Presets-1 sehingga kelihatan garis putih dipinggir segitiga warna abu-abu.

24. Langkah selanjutnya buatlah segitiga ukuran kecil, cara sama dengan cara pertama membuat segitiga siku-siku di atas (ambil segitiga dari Menu Insert, Klik Shapes, Pilih Segitiga Siku-Siku,

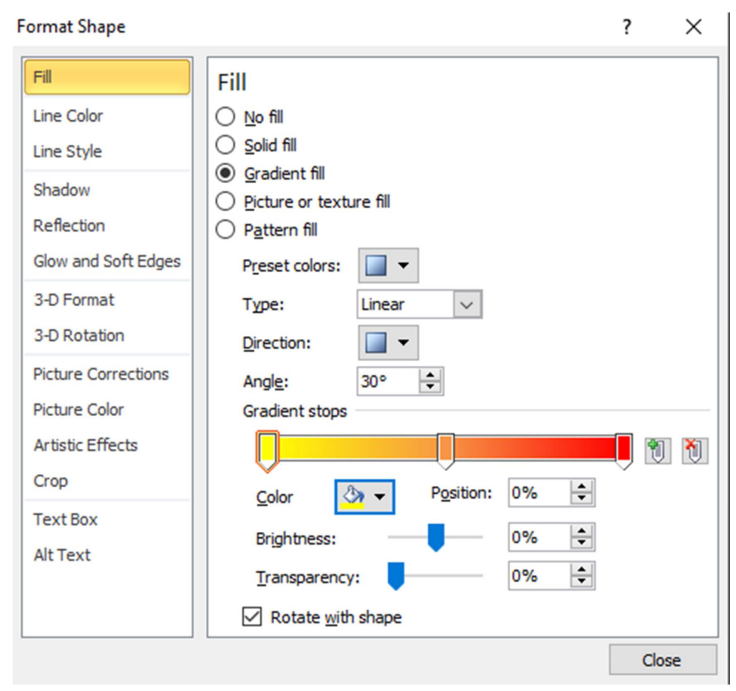

Gambar 5. Memberi warna gradiasi

25. Supaya lebih terang dan jelas, segitiga kecil dirubah warnanya dengan warna kuning, caranya sama dengan cara memberi warna pada segitiga sebelumnya di atas (dengan cara klik segitiga kecil tersebut, Pilih Menu Format, klik Shape Fill, Pilih dan Klik warna kuning),

26. Segitiga kecil tersebut dirubah menjadi melengkung, caranya sama dengan membuat lengkung/oval segitiga pertama di atas (Cara Pilih Menu Format, Klik Edit Shape dan Klik Edit Point, sehingga pada segitiga muncul titik hitam di setiap sudut segitiga serta garis merah di pinggir segitiga, tandanya segitiga siap untuk di edit).

27. Setelah bentuk segitiga kecil melengkung/oval seperti di atas, kemudian ganti warna gradiasi. 3 warna yaitu : kuning, orange, kuning. Caranya sama dengan memberi warna gradiasi segitiga sebelumnya di atas. Caranya klik segitiga kecil (objek yang akan diganti warnanya), dan klik mouse kanan sehingga muncul jendela menu, pilih Menu Format Shape. Tampil jendela Menu Format Shape, Klik Fill, Klik Gradien Fill, dan Pada bagian Type Pilih Linear, pada Bagian Angle pilih 20”. Stops paling kanan ganti warna kuning muda, dengan cara Klik Stop yang akan diganti warnanya, dan klik warna kuning muda. Begitu pula selanjutnya Stops tengah beri warna kuning tua, dan stops kiri warna kuning muda). 
28. Kemudian segitiga kecil tsb diberi effek dengan Pilih Menu Shape Effects, Pilih Presets dan Pilih Presets-2 sehingga kelihatan seperti berkilau di bagian pinggir segitiga.

29. Selanjutnya perlu gambar segitiga yang sama untuk di bagian bawah halaman kertas, cara termudah ketiga segitiga tersebut di copy, dengan cara klik ketiga segitiga dan tahan tombol Ctrl pada keyboard sambil ditarik ke bagian bawah (Gambar 6 kiri).

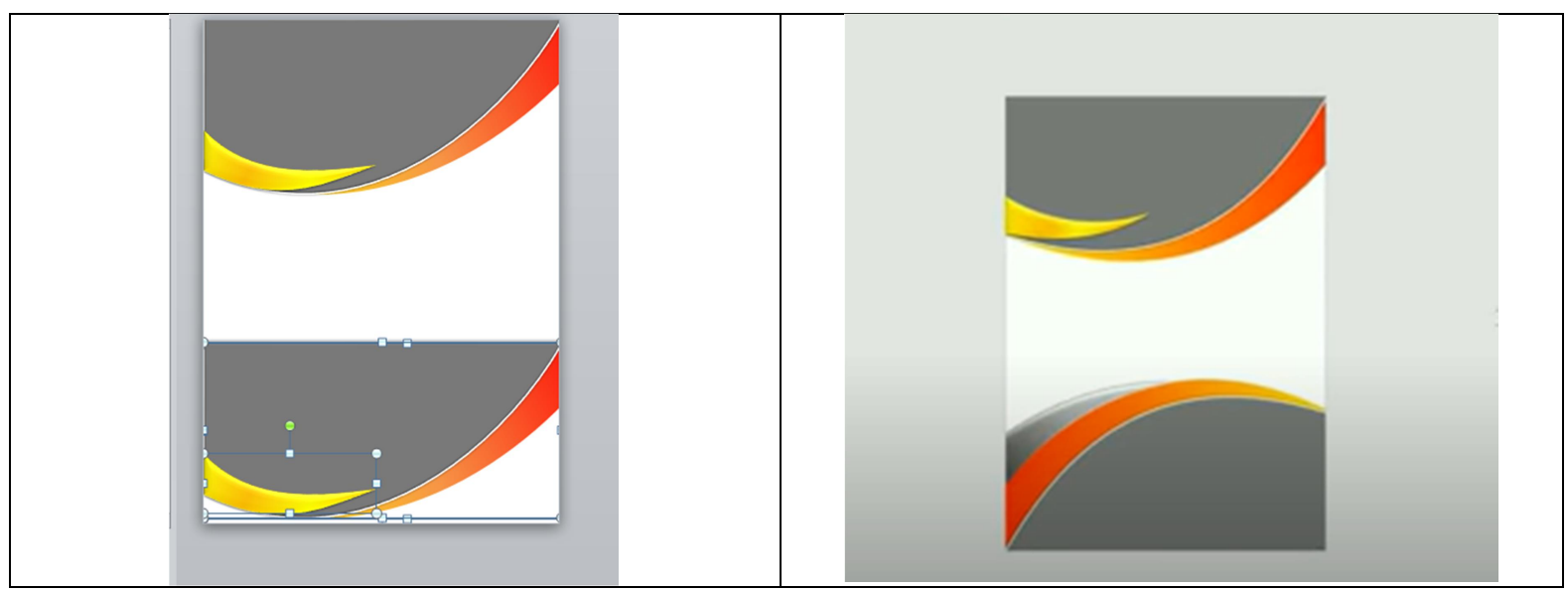

Gambar 6. Segitiga lengkung dicopy bersama ke bawah dan dibalik

30. Kemudian balik gambar segitiga bagian bawah tsb, dengan cara Pilih Menu Rotate, pilih Klik Flip Vertikal (Gambar 6 kanan).

31. Kemudian balik gambar segitiga, dengan cara Pilih Menu Rotate, Klik menu Flip Horizontal, Kemudian atur posisi segitiga-segitiga tersebut, dengan cara tarik ke atas terlebih dahulu segitiga yang berwarna orange ke atas, Kemudian klik segitiga orange, dan putar pada tanda putarnya, miringkan gambarnya agar lebih banyak muncul disebelah kiri.

32. Kemudian Segitiga kecil di atur posisinya ditarik ke bagian atas. Selanjutnya arah segitiga kecil dibalik, Pilih Menu Format, Klik Rotate dan Klik Flip Horizontal. Kemudian gambar segitiga kecil diatur posisinya yang tepat, dengan cara ditarik,

33. Selanjutnya warna segitiga kecil diganti dengan warna gradiasi abu-abu tua, abu-abu muda, putih. Caranya sama dengan cara gradiasi di atas (klik segitiga kecil (objek yang akan diganti warnanya), dan klik mouse kanan sehingga muncul jendela menu, pilih Menu Format Shape. Tampil jendela Menu Format Shape, Klik Fill, Klik Gradien Fill, dan Pada bagian Type Pilih Linear, pada Bagian Angle pilih 20”. Stops paling kanan ganti warna putih, dengan cara Klik Stop yang akan diganti warnanya, dan klik warna putih. Begitu pula selanjutnya Stops tengah beri warna putih, dan stops kiri warna abuabu) (Gambar 6 kanan). 
Pelatihan Desain Sampul Dengan MS.Word : Membuat Tugas Sekolah Siswa Yatim Marga Mulya Bekasi Lebih Menarik di Pandemi Covid-19

Budi Indrawati, Elia Rossa, Tyna Yunita, Tutiek Yoganingsih

34. Selanjutnya membuat kotak di bagian tengah kertas, caranya Pilih Menu Format. Klik Shapes, Pilih Klik Kotak. Letakkan gambar kotak di tengah halaman kertas:

35. Selanjutnya hilangkan garis pinggir kotak, caranya seperti di atas (Klik kotak dan Pilih Menu Format, Klik Shape Outline dan Klik No Outline).

36. Kemudian kotak diberi warna gradiasi orange muda, putih, putih. Caranya sama dengan di atas (Caranya klik kotak (objek yang akan diganti warnanya), dan klik mouse kanan sehingga muncul jendela menu, pilih Menu Format Shape. Tampil jendela Menu Format Shape, Pilih Fill, Pilih Gradien Fill, dan Pada bagian Type Pilih Linear, pada Bagian Angle pilih 20". Stops paling kanan ganti warna putih, dengan cara Klik Stop yang akan diganti warnanya, dan klik warna putih. Begitu pula selanjutnya Stops tengah beri warna putih, dan stops kiri warna orange muda) dan Klik Close (Gambar 7 kiri).

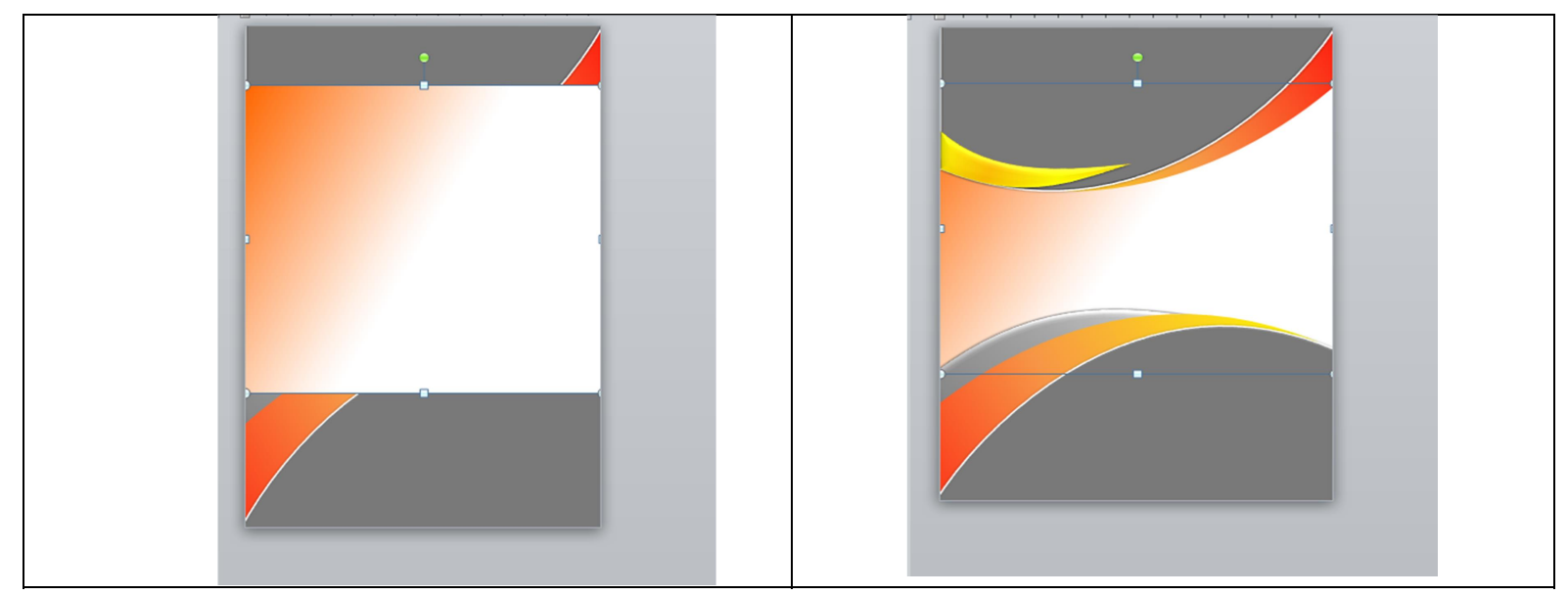

Gambar 7. Siapkan kotak di tengah untuk upload gambar dan di pindah ke belakang

37. Pindahkan kotak tersebut ke lapisan paling belakang. Dengan cara Klik kotak, dan Pilih Menu Format, Klik Send Backward. Klik Send To Back (Gambar 7 kanan).

38. Selanjutnya memberi gambar pada bagian tengah halaman ( pada kotak) dengan cara Klik kotak persegi tersebut, Pilih Menu Format, klik Picture Fill, pilih File...ambil gambar yang sudah disiapkan dan disimpan di dokumen folder dan klik insert (Gambar 8 kiri).

39. Jika gambar ingin diletakan di bagian bawah (dalam gambar oval), caranya hapus terlebih dahulu gambar dalam kotak (tengah)/batalkan. Dan Klik gambar oval yang di bawah, kemudian ikuti cara pengambilan gambar seperti di atas (dengan cara Klik segitiga warna abu-abu di bawah tersebut, Pilih Menu Format, klik Picture Fill, pilih File...ambil gambar yang sudah disiapkan dan di simpan di dokumen folder dan klik insert (Gambar 8 kanan). 
40. Berikutnya jika ingin memasukkan teks atau tulisan, misal di bagian atas. Caranya Pilih Menu Insert, klik Menu WordArt (Gambar 8 kanan).

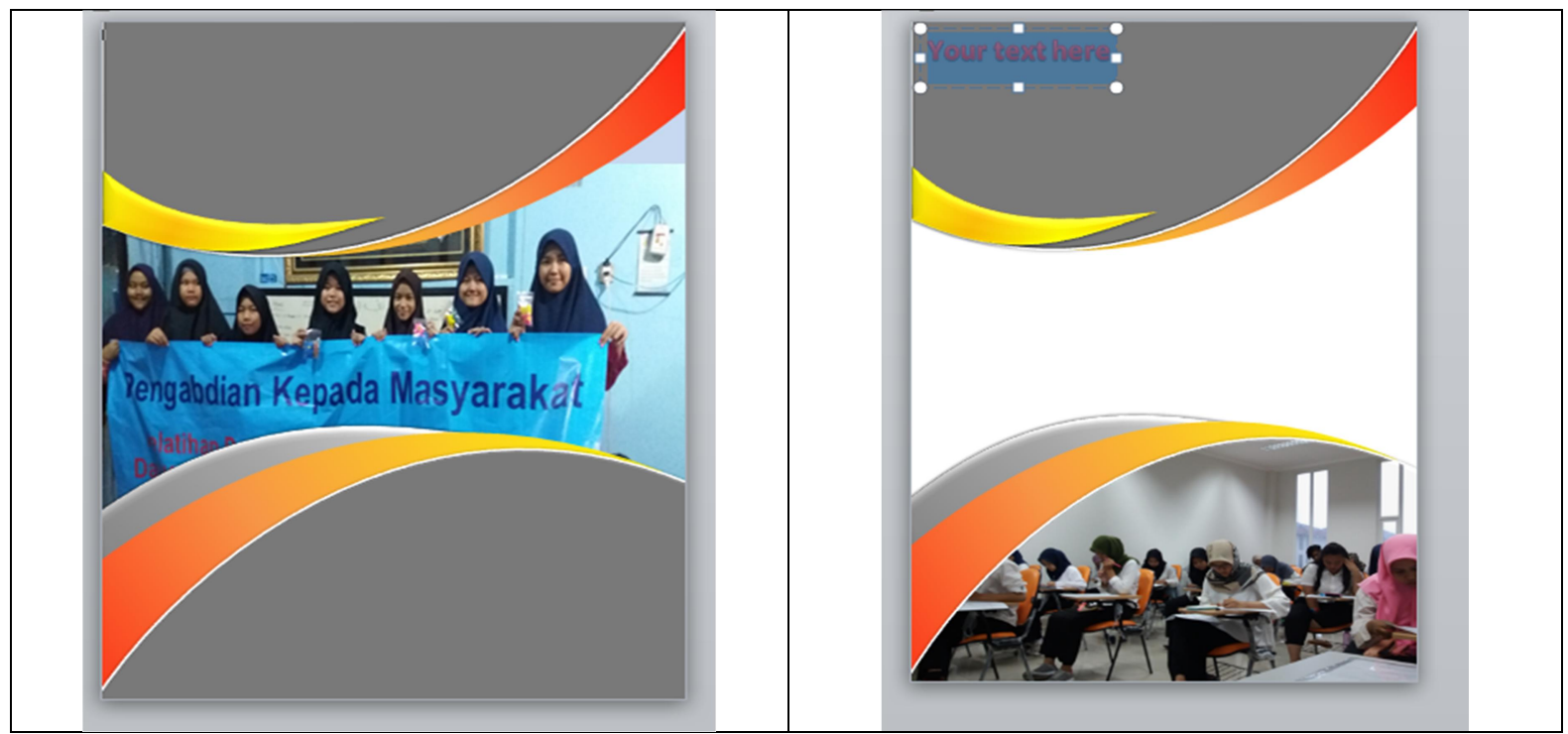

Gambar 8. Hasil upload foto di tengah dan atau di bawah serta beri judul nama

41. Pilih huruf misal yang standar (pojok kiri atas), bebas silakan pilih sesuai keinginan.

42. Ketik misal Judul : TUGAS MATA PELAJARAN BAHASA INDONESIA, dan bisa diganti type hurufnya atau ukuran hurufnya (Gambar 9).

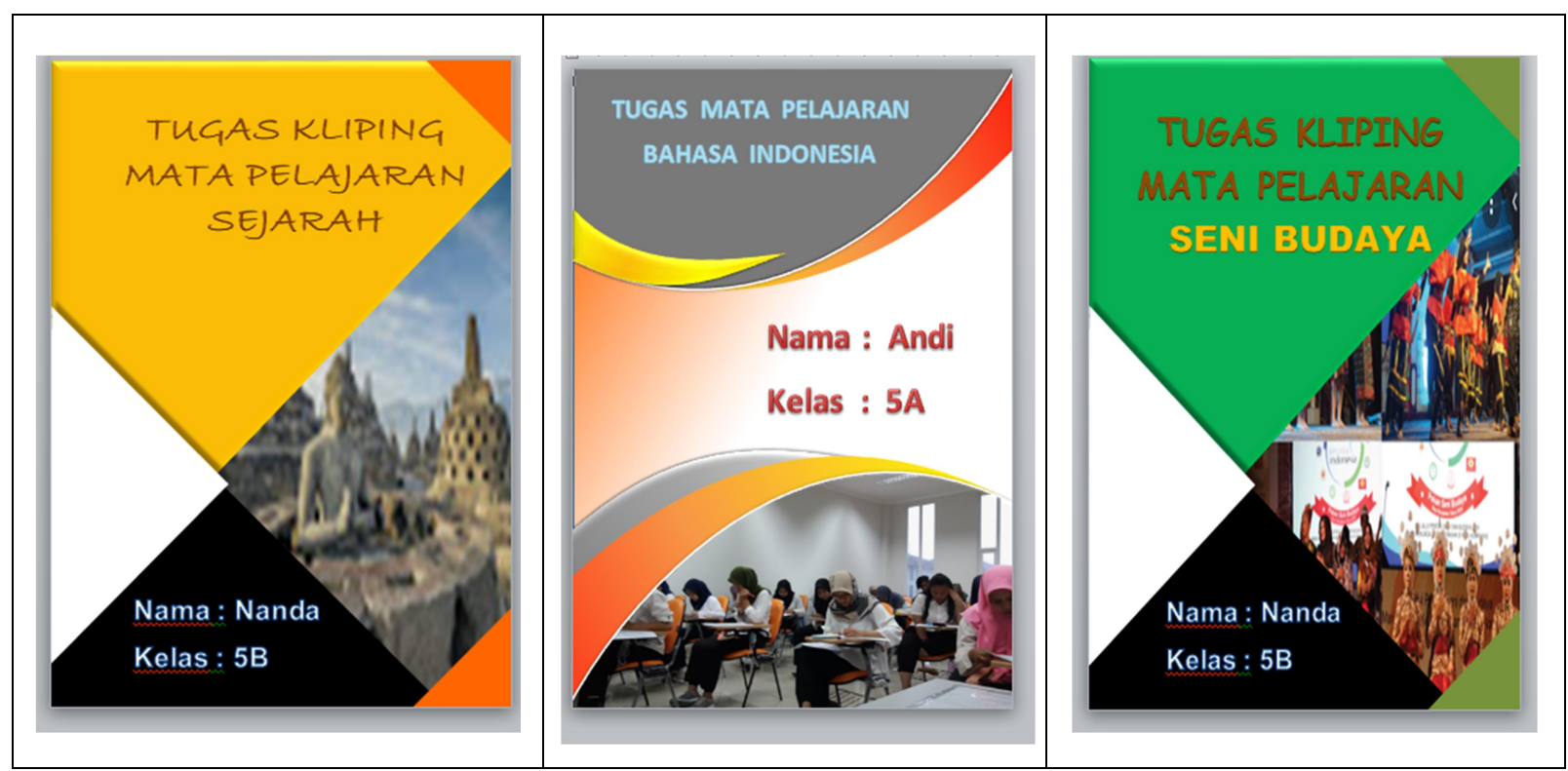

Gambar 9. Contoh hasil desain cover

Sumber : (bosstutorial.com, 2019)

Pada tahap evaluasi, dilakukan evaluasi untuk mengetahui peserta puas atau tidak puas terhadap pelatihan desain cover.

Teknik pengumpulan data dilakukan melalui kuesioner. Kepada setiap peserta setelah selesai pelatihan langsung diberikan kuesioner untuk penilaian terhadap pelaksanaan kegiatan pelatihan, tujuannya untuk mengetahui peserta puas atau tidak puas. 
Pelatihan Desain Sampul Dengan MS.Word : Membuat Tugas Sekolah Siswa Yatim Marga Mulya Bekasi Lebih Menarik di Pandemi Covid-19

Budi Indrawati, Elia Rossa, Tyna Yunita, Tutiek Yoganingsih

Penilaian menggunakan skala Likert, yaitu: Sangat Puas $(\mathrm{SP})=5$ :, Puas $(\mathrm{P})=4$ :, Cukup Puas $(\mathrm{CP})=3$ :, Tidak Puas $(\mathrm{TP})=2$, Sangat Tidak Puas $(\mathrm{STP})=1$.

Analisis data menggunakan evaluasi Kirkpatrick level reaksi (Level 1). Evaluasi level ini bertujuan untuk mengukur tingkat kepuasan peserta pelatihan terhadap penyelenggaraan pelatihan, mencakup penilaian materi, kemampuan intruktur, penyelenggara, serta fasilitas sarana (Rukmi et. al., 2014).

Data yang diperoleh dari pengukuran Level reaksi kemudian diolah dengan metode pembobotan dari Kirkpatrick. Perhitungan bobot untuk setiap pertanyaan kuesioner yang digunakan untuk mengukur sebagai berikut: a). Jumlahkan nilai jawaban dari seluruh responden untuk setiap item pernyataan kuesioner, b). Tentukan nilai tertinggi pada skala pengukuran, c). Hitung jumlah responden, d). Hitung bobot untuk setiap item pernyataan dengan rumus di bawah ini.

$$
\text { Bobot item ke }-\mathrm{i}=\frac{\text { Total nilai jawaban dari seluruh responden untuk item ke }-\mathrm{i}}{\text { Nilai tertinggi pada skala pengukuran } \mathrm{x} \text { Jumlah responden }} \times 100 \%
$$

Tabel 1. Kriteri Penilaian

\begin{tabular}{|l|l|}
\hline \multicolumn{1}{|c|}{ Range } & \multicolumn{1}{c|}{ Interpretasi } \\
\hline$<50 \%$ & Peserta menunjukkan reaksi yang kurang baik terhadap pelatihan \\
\hline $50-60 \%$ & Peserta menunjukkan reaksi yang lebih baik terhadap pelatihan \\
\hline $61-80 \%$ & $\begin{array}{l}\text { Peserta menunjukkan reaksi yang positif karena menyadari mendapat masukan } \\
\text { yang berguna selama pelatihan }\end{array}$ \\
\hline $81-100 \%$ & Peserta menunjukkan reaksi positif yang tinggi \\
\hline
\end{tabular}

(Sumber : (Rukmi et. al, 2014)

Penyajian data hasil perhitungan pengolahan data dalam bentuk jumlah dan persentase dibuatkan dalam tabel.

Alat dan bahan yang digunakan pada kegiatan pengabdian kepada masyarakat ini adalah laptop, infokus, modul, note book dan bolpen. Perlengkapan alat dan bahan tersebut dipersiapkan oleh tim pengabdian kepada masyarakat.

Terlebih dahulu dilakukan uji validitas dan uji reliabilitas terhadap pernyataanpernyataan yang digunakan dalam kuesioner pengabdian masyarakat ini. Hasil uji validitas pada pernyataan kuesioner yang terdiri dari 9 pernyataan, menunjukan semua pernyataan valid karena lebih besar dari tabel r $(0,666)$.

Hasil uji validitas pada tabel di bawah ini. Hasil Uji Reliabilitas ditunjukkan pada Tabel 3, menunjukkan nilai Cronbach's Alpha 0,934 berada di atas 0.7, dengan demikian dapat disimpulkan bahwa seluruh pernyataan dalam kuesioner dinyatakan reliabel. 
Sehingga kuesioner yang digunakan layak untuk mengukur 4 (empat) elemen: materi, instruktur, penyelenggaraan dan fasilitas.

Tabel 2. Uji Validitas

\begin{tabular}{lcccc}
\hline Variabel & Indikator & $\begin{array}{c}\text { Corrected } \\
\text { Item-Total } \\
\text { Correlation }\end{array}$ & $\begin{array}{c}\text { Nilai r } \\
\text { Tabel }\end{array}$ & Keputusan \\
\hline X & X1 & 0,776 & 0,666 & Valid \\
& X2 & 0,809 & 0,666 & Valid \\
& X3 & 0,735 & 0,666 & Valid \\
& X4 & 0,748 & 0,666 & Valid \\
& X5 & 0,706 & 0,666 & Valid \\
& X6 & 0,800 & 0,666 & Valid \\
& X7 & 0,776 & 0,666 & Valid \\
& X8 & 0,809 & 0,666 & Valid \\
& X9 & 0,706 & 0,666 & Valid \\
\hline
\end{tabular}

(Sumber: Output SPSS)

\begin{tabular}{|c|c|}
\hline \multicolumn{2}{|c|}{ Reliability Statistics } \\
\hline $\begin{array}{l}\text { Cronbach's } \\
\text { Alpha }\end{array}$ & $\mathrm{N}$ of Items \\
\hline .934 & 9 \\
\hline
\end{tabular}

Tabel 4. Skor dan Nilai Bobot

\begin{tabular}{|c|c|c|c|c|}
\hline No & Pernyataan & Skor & Bobot $\%$ & $\begin{array}{l}\text { Nilai Bobot } \\
\text { Rata-Rata } \\
\text { per Elemen }\end{array}$ \\
\hline 1 & $\begin{array}{l}\text { Metode penjelasan materi, langsung } \\
\text { praktek }\end{array}$ & 40 & 89 & $\begin{array}{c}\text { Materi } \\
91\end{array}$ \\
\hline 2 & $\begin{array}{l}\text { bermanfaat untuk peningkatan } \\
\text { pengetahuan / wawasan peserta }\end{array}$ & 42 & 93 & \\
\hline 3 & $\begin{array}{l}\text { Penjelasan instruktur mudah } \\
\text { dimengerti }\end{array}$ & 42 & 93 & $\begin{array}{l}\text { Instruktur } \\
\quad 92\end{array}$ \\
\hline 4 & $\begin{array}{l}\text { Intonasi instruktur dan kecepatan } \\
\text { berbicara }\end{array}$ & 41 & 91 & \\
\hline 5 & Pelaksanaan acara tepat waktu & 40 & 89 & Penyelenggaraan \\
\hline 6 & $\begin{array}{l}\text { Kesediaan panitia dalam membantu } \\
\text { peserta }\end{array}$ & 39 & 87 & 88 \\
\hline 7 & Konsumsi & 40 & 89 & Fasilitas \\
\hline 8 & Seminar Kit & 42 & 93 & 90 \\
\hline 9 & Fasilitas dan ruangan & 40 & 89 & \\
\hline
\end{tabular}

Tabel 4 di atas menjelaskan hasil penilaian peserta terhadap materi, instruktur, penyelenggaraan dan fasilitas pendukung pelatihan. Diperoleh nilai bobot berada di antara $87 \%$ dan 93\%. Persentase bobot terbesar terdapat pada pernyataan nomor 2 (bermanfaat untuk peningkatan pengetahuan/wawasan peserta) sebesar 93\%, dan nomor 3 (Penjelasan dari instruktur) sebesar 93\%, dan nomor 8 (seminar kit). Secara keseluruhan semua bobot pernyataan di atas 87\%, artinya ini berada di range keempat (Lihat Tabel 1) dengan 
Pelatihan Desain Sampul Dengan MS.Word : Membuat Tugas Sekolah Siswa Yatim Marga Mulya Bekasi Lebih Menarik

interpretasi bahwa peserta menunjukkan reaksi yang positif yang tinggi. Dengan demikian, disimpulkan bahwa peserta pelatihan puas terhadap pelatihan desain cover makalah dan tugas sekolah ini. Sub elemen yang masih perlu untuk ditingkatkan lagi adalah kesediaan panitia dalam membantu peserta, sub elemen tersebut memiliki bobot yang relatif lebih kecil dibandingkan sub elemen yang lain. Teknik evaluasi pelatihan dengan metode pembobotan dari Kirkpatrick ini juga dilakukan oleh Rukmi et. al. (2014).

Hal yang sama dilakukan oleh Lisnawita et.al dalam mengevaluasi pelatihan pada kegiatan pengabdian kepada masyarakat dengan cara pengisian kuesioner yang disebar kepada peserta di akhir pelatihan, namun bedanya Lisnawita et.al menggunakan skala Guttman (Lisnawita et.al, 2020).

Kegiatan pengabdian kepada masyarakat ini diharapkan memberikan efek positif dalam pengembangan mental kemandirian generasi muda. Harapan ini juga didukung dari kegiatan pengabdian kepada masyarakat yang dilakukan oleh Aditya Ashadul Ushud, Achmad, bahwa kegiatan ini secara tidak langsung menjadi bagian untuk turut menambahkan pengetahuan dan kemampuan sebagai bekal dalam mengerjakan tugas sekolah maupun pekerjaan nanti (Aditya Ashadul Ushud, 2020).

\section{KESIMPULAN DAN SARAN}

\section{Kesimpulan}

Hasil dari kegiatan pengabdian kepada masyarakat dalam bentuk pelatihan desain cover dengan Word, yaitu peserta siswa:1). Dapat meningkatkan semangat baru dalam pembelajaran pada masa pandemi covid-19. 2). Dapat membuat desain cover makalah dengan menggunakan Microsoft Word, terutama dalam pembuatan makalah dan tugastugas sekolah melalui pemberian warna-warna menarik dari makalah tugas-tugas sekolah. 3). Mengetahui dan paham bahwa Word dapat mendesain cover suatu makalah, buku, dan lainnya. 4). Dapat dan mudah membuat desain cover dengan Word, sehingga dapat menciptakan kreativitas siswa remaja serta dapat dijadikan sebagai suatu hobby. 5). Dapat dijadikan sebagai bekal ketrampilan dalam bekerja

Hasil evaluasi dari pelatihan desain cover dengan Word, menunjukan bahwa peserta pelatihan puas dengan pelaksanaan pelatihan desain cover makalah dan tugas sekolah ini, dilihat dari interpretasinya bahwa peserta menunjukkan reaksi positif yang tinggi.

\section{Saran}

Permasalahan siswa yatim dan dhuafa Sahabat Yatim Indonesia adalah selain fasilitas pendidikan, adalah ketrampilan. Untuk itu perlu memberikan ketrampilan dari dini 
agar menimbulkan hobby serta kreativitas siswa yang dapat dikembangkan untuk bekal ketrampilan bekerja nantinya, sehingga kelak mengurangi ketergantungan kepada yayasan, diantaranya pelatihan ketrampilan computer excel serta kerajinan tangan lainnya yang terkait dengan pelajaran di sekolah.

\section{UCAPAN TERIMAKASIH.}

Kegiatan Pengabdian Kepada Masyarakat ini dapat terselenggara dengan adanya dukungan dari beberapa pihak. Untuk itu kami mengucapkan terima kasih dan penghargaan sebesar-besarnya kepada : Dekan Fakultas Ekonomi dan Bisnis, Kepala LPPMP, Kepala Biro Keuangan Universitas Bhayangkara Jakarta Raya. Kepala asrama Sahabat Yatim Indonesia Marga Mullya Bekasi.

\section{DAFTAR PUSTAKA}

Aditya Ashadul Ushud, A. (2020). Pelatihan Desain Grafis Menggunakan Microsoft Publisher bagi Remaja Islam Masjid Darussalam (RISMADA). JURNAL ABDIMAS BSI - Jurnal Pengabdian Kepada Masyarakat Universitas Bina Sarana Informatika, 3.

bosstutorial.com. (2019). Cara buat cover cantik dengan Microsoft Word. Bosstutorial.Com. https://www.bosstutorial.com/2019/06/cara-membuat-covercantik-dengan-Microsoft-Word.html

Contohposter.com. (2020). Cara buat cover cantik dengan word cover makalah. Contohposter.Com. https://contohposter.com/terbaru/contoh-poster-edukasi/carabuat-cover-cantik-dengan-word-cover-makalah

Larenta Apriyanti. (2020). Microsoft Word For Design. Elex Media Komputindo.

Lisnawita et.al. (2020). Pelatihan Desain Grafis Untuk Meningkatkan Kreatifitas Siswa. DINAMISIA - Jurnal Pengabdian Kepada Masyarakat Universitas Lancang Kuning, 4.

Nizam, P. D. D. (2020). Menakar Pendidikan Pasca Pandemi COVID-19. http://www.dikti.go.id/highlight/menakar-pendidikan-pasca-pandemi-covid19/?utm_source=

feedburner\&utm_medium $=$ feed\&utm_campaign $=$ Feed $\% 3 \mathrm{~A}+$ go $\% 2 \mathrm{Fdikti}+\% 28 \mathrm{Direkt}$ orat + Jenderal+Pendidikan+Tinggi $\% 2 \overline{9}$

Raafi'udin. (2020). PENINGKATAN DESAIN GRAFIS UNTUK MENINGKATKAN KREATIFITAS DAN MENAMBAH DAYA SAING MASYARAKAT KECAMATAN PASAR MINGGU JAKARTA SELATAN. Jurnal Abdimas SULUH, 2, 70-77.

Rukmi et. al. (2014). Evaluasi Training Dengan Menggunakan Model Kirkpatrick (Studi Kasus Training Foreman Development Program Di PT. Krakatau Industrial Estate Cilegon). Perpustakaan Itenas. lib.itenas.ac.id

sahabatyatim.com. (2021). Profil Sahabat Yatim. Sahabatyatim.Com. https://www.sahabatyatim.com 